\title{
The Competing Influences of Initial Depressive Symptomatology and Early Alliance on Early Outcome: A Preliminary Study
}

\author{
Giorgio Gabriele Alberti $^{1 \bowtie}$, Anna Martorano ${ }^{2}, \&$ Bruno Martorano $^{3}$
}

\begin{abstract}
We examined 40 psychotherapies, some delivered in combination with pharmacotherapy, which were all conducted by cognitive behavioral or psychodynamically oriented therapists in a general hospital center for the treatment of light to moderate depressive disorders. Our goal was to examine the relationship between early outcome (defined as change in Beck Depression Inventory scores between sessions 2 and 15) and early therapy alliance (as measured at sessions 1 to 5 by the Working Alliance Inventory). We also wanted to concurrently examine the effect of initial depressive symptomatology (BDI at session 2) on early outcome. For the entire sample, both early alliance and initial depressive symptomatology were found to significantly correlate with outcome, the latter more strongly so. However, after dividing the patient sample into subgroups based on different initial levels of depression, early outcome for patients with depression of intermediate severity was found to be better predicted by early alliance than by initial depression. These results suggest that there may be a patient subgroup for whom a good early alliance optimally mitigates the self-perpetuating action of initial depression.
\end{abstract}

Keywords: therapeutic alliance, outcome predictors, depression

This study is part of a broader research project which began in 2006 at the Center for Dysthymic Disorders, San Carlo Hospital, Milan (Alberti, Rognoni, Carozzi, \& Alfieri, 2008a). The aim of this project was to study the formation of the therapeutic alliance and the relationship between early alliance and therapy outcome (Alberti, 2009; Alberti, Rognoni, Alfieri, Carozzi, Martorano, Ricchi, Martini, 2008b; Alberti, Rognoni, Carozzi, Alfieri, Martorano, Ricchi, Martini 2008c).

Apart from finding a positive correlation between early alliance and outcome, a peculiar aspect of our data

\footnotetext{
${ }^{1}$ Milan University, Medical Faculty, Specialization School in Clinical Psychology.

${ }^{2}$ Milan University, Medical Faculty, Specialization School in Clinical Psychology.

${ }^{3}$ The United Nations Children's Fund (UNICEF) Office of Research - Innocenti of Psychology, University of Palermo, Italy.

Correspondence concerning this paper should be addressed to Giorgio Gabriele Alberti, Piazza Lega Lombarda 1, 20154 Milano, Italy.

E-mail: dr.gg.alberti@studiomedicodipsicoterapia.com
}

was an even stronger correlation between patients' initial depression and their depression at a later stage of therapy, that is at session 15 (Alberti et al., 2008c). In other words, although a strong early alliance, measured at sessions 3 to 5 , significantly correlated with a reduction of depression at later sessions (with Pearson's $r$ varying from - .33 to -.38 ), depression reported at the beginning of therapy was much more significantly correlated with depression reported later in therapy, (with Pearson's $r$ reaching .78).

This suggested a sort of 'inertia' of initial depression, or a tendency for depression to perpetuate in time, even when it was offset against the opposing action of a good therapy alliance (and, of course, of other factors mobilized or facilitated by it). In this study we decided to focus on the opposing factors that influence outcome in order to potentially highlight their dynamics.

Psychotherapy outcome is reliably predicted on the basis of different factors, which can be divided into three categories: patient factors (e.g., psychological mindedness, attachment modality, internal object relations, expectations about treatment, symptomatology and others, Clarkin \& Levy, 2004), therapist factors (e.g., clinical experience, relational attitude, attachment modality, 
etc., Beutler et al., 2004), and factors that arise during the initial phase of the therapy process, as a consequence of alliance fostering attitudes and procedures (Alberti, 2004; Safran \& Muran, 2000). A great deal of research has been carried out into the therapeutic alliance, which plays a central role in the third category (Horvath \& Symonds, 1991; Lingiardi, 2002; Martin, Garske, \& Davis, 2000). All of the above factors can positively or negatively correlate with outcome. By considering them not only as statistical predictors but also as factors that contribute to the clinically efficacious therapeutic process, we must establish whether they facilitate or hinder good therapeutic activity.

The interplay between factors that facilitate and hinder outcome has been highlighted by Kazdin (2007, 2009), who distinguishes three general, fundamental concepts: change mediators, change mechanisms, and mechanism moderators. Change mediators are intervening variables that statistically account for the relationship between a therapeutic procedure and its outcome. They do not necessarily correspond to a change mechanism. Kazdin points out that something that mediates change may not necessarily explain how change comes about. Indeed, the mediator can be either a proxy for one or more other variables, or a general construct that is not necessarily intended to explain the mechanisms of change. A mediator may be a guide that indicates possible mechanisms, but it is not necessarily one of them. On the contrary, a change mechanism encompasses the processes or events that are responsible for the change, thus the reasons why change comes about. Finally, a moderator is conceived as a factor that influences change mechanisms either by reducing or increasing them.

Kazdin's (2007, 2009) scheme provides a conceptual framework within which the interplay of opposing factors that contribute to the outcome found in our previous research can be interpreted. The intensity of the early alliance can be conceptualized as a mediator of the actual change mechanism. From this perspective, initial depression can be re-defined as a moderator, which negatively impinges on the alliance's impact on clinical change, thereby thwarting it (e.g., Hoberman, Lewinsohn, \& Tilson, 1988). In the present study, we focused on early outcome, that is, a significant change in any problematic domain of a client within the initial phases of the treatment. More specifically, we examined whether variations in initial depression moderate or differentially influence the alliance and therapy early outcome.

To this end we examined the correlation between early alliance and depression at session 15 (i.e., early outcome) in subgroups of patients differing in their mean initial depression level, i.e. the intensity of the moderating factor. Our hypothesis was that patients with different initial depression level would show different correlations between early alliance and depression at session 15. Moreover, we were interested in exploring what configuration would assume these different correlations. We thought that with increasing initial depression the correlation between early alliance and early outcome would simultaneously diminish.

\section{Method}

\section{Patient Sample and Treatments}

We examined data pertaining to 40 short- to mediumterm psychodynamic $(n=24)$ and cognitive-behavioral $(n=16)$ psychotherapies, given in weekly sessions by five therapists in an outpatient setting. Patients were affected by the following disorders: dysthymia anxiety and adjustment disorders and cluster $\mathrm{C}$ personality disorders. All patients manifested predominantly depressive symptoms of low to medium severity, having a BDI (Beck Depression Inventory, Beck \& Steer 1987) average score at the beginning of therapy of 18.41. Exclusion criteria were: dementia, other organic diseases impinging on brain functioning (e.g., liver cyrrhosis), acute or chronic psychosis, major depression, manic or hypomanic condition, severe personality disorder (e.g. paranoid or antisocial and severe borderline), current substance abuse.

In about $60 \%$ of patients and in both psychotherapeutic modalities, clients also received pharmacological treatment with tranquilizers and mainly selective serotonin reuptake inhibitors (SSRI) antidepressants. In the majority of such cases, the onset of medication preceded the onset of psychotherapy, which was recommended by the treating psychiatrist because medication alone had not produced satisfactory results.

\section{Measure and Procedures}

Upon arrival at the Center for Dysthymic Disorders, patients underwent an intake interview in which they were asked to describe their problem to the therapist, who decided whether or not to treat them. In the context of a broader research project (Alberti et al. 2008b, 2008c) a general assessment procedure was then carried out on the patients who were deemed suitable for therapy. An array of symptom scales were administered at session 2, and then re-administered at sessions 15, 30 and 45: Hamilton Anxiety Scale (HAS; Hamilton 1959), Hamilton Depression Scale (HDS; Hamilton 1960), Zung Anxiety Scale (ZAS; Zung 1971), Zung Depression Scale (ZDS; Zung 1965), Symptom Check-List-90 SCL90 (Derogatis 1977), Brief Psychiatric Rating Scale (BPRS; Overall \& Gorham 1962), and Beck Depression Inventory (BDI; Beck \& Steer 1987).

Patient-reported alliance measures were made by using the short form of the patient version of Horvath and Greenberg's Working Alliance Inventory (WAI; Horvath \& Greenberg, 1989) with 12 items.

For the present study we used only a part of the data: the WAI (Horvath \& Greenberg, 1989) total and partial scores (Task, Goal and Bond), administered at sessions 2, 3, 4, and 5, and to the BDI (Beck \& Steer, 1987) scores, administered at sessions 2 and 15 .

\section{Statistical Data Analysis}

Statistical analyses included partial correlations and 
Table 1. Partial correlations between advanced depression (session 15) and respectively initial depression (session 2) and early alliance (sessions 2 to 5), controlling respectively for early alliance and for initial depression

\begin{tabular}{llllll}
\hline Variable & BDI-t2 & WAI-t2 & WAI-t3 & WAI-t4 & WAI-t5 \\
\hline BDI-t15 & $0.77^{* *}$ & -0.24 & -0.24 & $-0.33^{*}$ & $-0.38^{*}$ \\
\hline
\end{tabular}

${ }^{*} p<.05 ;{ }^{* *} p<.01$.

Note $\mathrm{BDI}=$ Beck Depression Inventory; WAI = Working Alliance Inventory; $\mathrm{t} 2, \mathrm{t} 3, \mathrm{t} 4, \mathrm{t} 5, \mathrm{t} 15=$ session number at which instruments were administered

multiple regressions. Partial correlations were used to test hypothesis of a correlation of early outcome with respectively initial depression (controlling for early alliance) and early alliance (controlling for initial depression), Multiple regression was used to assess the degree of association of early alliance and initial depression (independent variables) on outcome at session 15 (dependent variable). These two statistical methods, which estimate the contribution of independent variables to early outcome in two different ways, are thus complementary and could potentially corroborate each other.

\section{Results}

\section{Correlations between initial depression, early alli- ance and early outcome}

The BDI score variation between session 2 and 15, of
-4.46 points, shows a clear significant decrease $(\mathrm{t}=$ $4.7951, p<.01$ ), that is, a positive therapy early outcome. Although on a smaller scale, alliance also strengthened significantly between sessions 2 and 5 , rising by 2.75 points on the WAI scale $(t=2.2972, p<$ $.05)$.

Table 1 shows the partial correlations between depression at session 15 and respectively initial depression and early alliance, controlling respectively for alliance and for initial depression. It is evident that initial depression showed a high partial correlation with advanced depression.

Smaller partial correlation coefficients were found between early alliance and depression at session 15 . Although it became progressively larger from session 2 to session 5, this relationship was only statistically significant at sessions 4 and 5. Therefore, with respect to early outcome, two opposing relationships were found. Initial depression had a negative, stronger relationship

Table 2. Effects of initial depression (session 2) and alliance (sessions 2, 3, 4, 5 and 15) on advanced depression (session $15)$ as shown by multiple regression analysis

\begin{tabular}{lcccc}
\hline & \multicolumn{3}{c}{$\mathrm{n}=40$} \\
\cline { 2 - 5 } Variable & $\beta$ & $\mathrm{T}$ & $\mathrm{R}^{2}$ & $\mathrm{~F}$ \\
\hline Model 1 & & & 0.63 & $30.40^{* *}$ \\
Constant & 10.89 & 1.61 & & \\
BDI-t2 & $0.70^{* *}$ & 6.08 & & $32.64^{* *}$ \\
WAI-t2 & -0.15 & -1.68 & 0.62 & \\
Model 2 & & & & \\
Constant & 9.83 & 1.45 & & $36.54^{* *}$ \\
BDI-t2 & $0.71^{* *}$ & 6.10 & & \\
WAI-t3 & -0.13 & -1.55 & & \\
Model 3 & 14.04 & 1.94 & & \\
Constant & $0.68^{* *}$ & 5.80 & & \\
BDI-t2 & -0.19 & -2.03 & & \\
WAI-t4 & & & & \\
Model 4 & 7.01 & 1.32 & & \\
Constant & $0.72^{* *}$ & 6.38 & & \\
BDI-t2 & -0.10 & -1.39 & & \\
WAI-t5 & & & & \\
Model 5 & 13.66 & 1.97 & & \\
Constant & $0.69^{* *}$ & 6.07 & & \\
BDI-t2 & $-0.17^{* *}$ & -1.86 & & \\
WAI-t15 & & &
\end{tabular}

${ }^{*} p<.05 ;{ }^{* *} p<.01$

Note. $\mathrm{BDI}=$ Beck Depression Inventory; $\mathrm{WAI}=$ Working Alliance Inventory; $\mathrm{t} 2, \mathrm{t} 3, \mathrm{t} 4, \mathrm{t} 5, \mathrm{t} 15=$ session number at which instruments were administered. 
Table 3. Partial correlations between advanced depression (session 15) and respectively initial depression (session 2) and the three factors Task, Bond and Goal or early alliance (sessions 2 to 5), controlling respectively for early alliance and initial depression

\begin{tabular}{|c|c|c|c|c|c|c|c|c|c|c|c|c|c|}
\hline \multirow[b]{2}{*}{ Variable } & \multirow[t]{2}{*}{ BDI-t2 } & \multicolumn{3}{|c|}{ WAI-t2 } & \multicolumn{3}{|c|}{ WAI-t3 } & \multicolumn{3}{|c|}{ WAI-t4 } & \multicolumn{3}{|c|}{ WAI- -5} \\
\hline & & Task & Bond & Goal & Task & Bond & Goal & Task & Bond & Goal & Task & Bond & Goal \\
\hline BDI-t15 & $0.77^{* *}$ & -0.06 & -0.19 & 0.10 & $-0.32^{\dagger}$ & 0.07 & 0.09 & 0.08 & -0.15 & -0.07 & $0.39^{*}$ & -0.06 & -0.15 \\
\hline
\end{tabular}

${ }^{\dagger} p<.10 ;{ }^{*} p<.05 ;{ }^{* *} p<.01$

Note. $\mathrm{BDI}=$ Beck Depression Inventory; $\mathrm{WAI}=$ Working Alliance Inventory; $\mathrm{t} 2, \mathrm{t} 3, \mathrm{t} 4, \mathrm{t} 5, \mathrm{t} 15=$ session number at which instruments were administered.

with the outcome at session 15 compared to the early alliance, which had a positive relationship with early outcome.

We conducted a multiple regression analysis (Table 2 ) in order to test for either independent or mediation effects between the prediction of early outcome of these two variables at session 15 . This analysis indicates that the coefficient of variable BDI at session $2(\mathrm{t} 2)$ is always positive and statistically significant at the $1 \%$ level. In particular, a unitary variation of BDI at session 2 corresponds to a variation of BDI at session 15 lying within a range between .68 and .72 . On the other hand, the WAI variable pertaining to different sessions never reaches significance, except in session 4, where it is negative and significant at the $5 \%$ level.

Table 3 shows the partial correlations of depression at session 15 with initial depression and with the three component factors of the WAI scale (Task, Bond and Goal), controlling respectively for early alliance and for initial depression.

It can be seen that there is a very significant strong correlation between advanced and initial depression.
With regard of therapeutic alliance, early outcome shows a moderate significant correlation only with the Task subscale (agreement on what needs to be done during sessions) at session 5 .

\section{Subgroups with different initial depression level}

Thus far, the data has confirmed what had already been shown for the larger sample and for longer-term outcome (Alberti, Rognoni, Alfieri, et al., 2008b; Alberti, Rognoni, Carozzi, et al., 2008c), that is, that initial depression is a much stronger predictor of (early) outcome than early alliance.

Relevant empirical evidence (Lambert \& Ogles, 2004) demonstrates that said predictors can also be considered as outcome-influencing factors. One could argue that their action may also be indirect as they may exert their influence through a cascade of other events that are favorable and unfavorable to therapeutic change. In the present study we infer that the outcome of session 15 might be good if the positive effect of early

Table 4. Descriptive statistics of the assessed variables in the four subgroups of the total sample, differentiated according to their initial depression

\begin{tabular}{|c|c|c|c|c|c|c|c|c|c|c|}
\hline \multirow[b]{2}{*}{ Variable } & \multicolumn{2}{|c|}{$\begin{array}{c}\text { Minimal } \\
\text { Depression }^{\text {Level }} \\
(\mathrm{n}=14)\end{array}$} & \multicolumn{2}{|c|}{$\begin{array}{c}\text { Moderate } \\
\text { Depression } \text { Level }^{\mathrm{b}} \\
(\mathrm{n}=32)\end{array}$} & \multicolumn{2}{|c|}{$\begin{array}{l}\text { Pathological } \\
\text { Depression } \\
\text { Level }^{\mathrm{c}} \\
(\mathrm{n}=16)\end{array}$} & \multicolumn{2}{|c|}{$\begin{array}{c}\text { Severe } \\
\text { Depression }^{\text {Level }} \\
(\mathrm{n}=8)\end{array}$} & \multicolumn{2}{|c|}{$\begin{array}{l}\text { Total sample } \\
\quad(\mathrm{n}=40)\end{array}$} \\
\hline & M & $S D$ & M & SD & M & SD & M & $S D$ & M & $S D$ \\
\hline BDI-t2 & 8.79 & 4.96 & 15.94 & 7.44 & 25.00 & 6.13 & 32.88 & 3.83 & 19.32 & 9.68 \\
\hline BDI-t15 & 6.57 & 5.89 & 12.16 & 7.41 & 18.85 & 7.06 & 24.13 & 8.03 & 14.55 & 8.87 \\
\hline WAI-t2 & 67.36 & 11.41 & 64.97 & 10.86 & 63.73 & 10.10 & 65.13 & 10.02 & 65.00 & 10.58 \\
\hline WAI-t3 & 67.57 & 9.57 & 64.84 & 10.80 & 64.88 & 10.55 & 69.75 & 6.18 & 65.82 & 10.18 \\
\hline WAI-t4 & 71.07 & 9.90 & 68.13 & 10.76 & 66.19 & 9.72 & 67.00 & 6.02 & 67.90 & 9.94 \\
\hline WAI- $t 5$ & 71.71 & 9.68 & 68.25 & 10.48 & 65.62 & 10.23 & 65.75 & 10.22 & 67.75 & 10.35 \\
\hline
\end{tabular}

${ }^{\mathrm{a}} \mathrm{BDI}<17 .{ }^{\mathrm{b}} \mathrm{BDI}<29 .{ }^{\mathrm{c}} \mathrm{BDI}>16 .{ }^{\mathrm{d}} \mathrm{BDI}>28$.

Note. $\mathrm{BDI}=$ Beck Depression Inventory; $\mathrm{WAI}=$ Working Alliance Inventory; $\mathrm{t} 2, \mathrm{t} 3, \mathrm{t} 4, \mathrm{t} 5, \mathrm{t} 15=$ session number at which instruments were administered. 
Table 5. Partial correlations between advanced depression (session 15) and respectively initial depression (session 2) and early alliance (sessions 2 to 5 ) in the four depression level subgroups, controlling for respectively early alliance and initial depression

\begin{tabular}{|c|c|c|c|c|c|}
\hline \multirow[b]{2}{*}{ Variable } & \multicolumn{5}{|c|}{ Minimal level $(n=14)$} \\
\hline & BDI-t2 & WAI-t2 & WAI-t3 & WAI-t4 & WAI-t5 \\
\hline \multirow[t]{3}{*}{ BDI-t15 } & $0.71^{* *}$ & 0.15 & 0.32 & 0.01 & 0.01 \\
\hline & \multicolumn{5}{|c|}{ Moderate level $(n=32)$} \\
\hline & BDI-t2 & WAI-t2 & WAI-t3 & WAI-t4 & WAI-t5 \\
\hline \multirow[t]{3}{*}{ BDI-t 15} & $0.77^{* *}$ & -0.25 & $-0.33^{\dagger}$ & $-0.37^{*}$ & $-0.37^{*}$ \\
\hline & \multicolumn{5}{|c|}{ Pathological level $(n=26)$} \\
\hline & $\mathrm{BDI}-\mathrm{t} 2$ & WAI-t2 & WAI-t3 & WAI-t4 & WAI-t5 \\
\hline \multirow[t]{3}{*}{ BDI-t 15} & $0.47^{*}$ & $-0.39^{*}$ & $-0.37^{\dagger}$ & $-0.42^{*}$ & $-0.49^{*}$ \\
\hline & \multicolumn{5}{|c|}{ Severe level $(n=8)$} \\
\hline & BDI-t2 & WAI- $t 2$ & WAI- $\mathrm{t} 3$ & WAI-t4 & WAI- $\mathrm{t} 5$ \\
\hline BDI-t15 & $-0.09^{* *}$ & -0.44 & -0.10 & -0.29 & $-0.72^{\dagger}$ \\
\hline
\end{tabular}

${ }^{\dagger} p<.10 ;{ }^{*} p<.05 ;{ }^{* *} p<.01$

Note $\mathrm{BDI}=$ Beck Depression Inventory; WAI = Working Alliance Inventory; $\mathrm{t} 2, \mathrm{t} 3, \mathrm{t} 4, \mathrm{t} 5, \mathrm{t} 15=$ session number at which instruments were administered

alliance is sustained, and if the negative effect of initial depression is reduced.

In this perspective, Kazdin's $(2007,2009)$ concepts of change mediator and change moderator are particularly useful to help us understand the overall change mechanism of our therapy sample. We can conceive of alliance as a change mediator whose action may be inhibited and reduced by the patient's symptomatic condition at the beginning of therapy, or by secondary related moderating factors.

On this basis, we assumed that the inhibitory moderating influence of initial depression depends on its intensity level. We therefore decided to explore the alliance- outcome correlation in patient groups that differ in their initial depression level. To this end we re-grouped the patients on the basis of their initial BDI score.

According to criteria suggested by Beck (Beck \& Steer 1987), we created four subgroups with increasing mean initial depression (Figure 1), denominated as follows:

(a) Subgroup with minimal depression level: BDI score between 1 and 16;

(b) Subgroup with moderate depression level: BDI score between 1 and 28;

(c) Subgroup with pathological depression level: BDI score between 17 and 63;

Table 6. Descriptive statistics of the intermediate depression level subgroup and of the total sample

\begin{tabular}{|c|c|c|c|c|}
\hline \multirow[b]{2}{*}{ Variable } & \multicolumn{2}{|c|}{ Intermediate subgroup $(\mathrm{n}=18)$} & \multicolumn{2}{|c|}{ Total sample $(\mathrm{n}=40)$} \\
\hline & M & SD & M & SD \\
\hline BDI-t2 & 21.50 & 2.66 & 19.33 & 9.68 \\
\hline BDI-t15 & 16.50 & 5.27 & 14.55 & 8.87 \\
\hline WAI-t2 & 63.11 & 10.36 & 65.00 & 10.58 \\
\hline WAI-t3 & 62.72 & 11.48 & 65.83 & 11.18 \\
\hline WAI-t4 & 65.83 & 11.12 & 67.90 & 9.94 \\
\hline WAI-t5 & 65.56 & 10.53 & 67.75 & 10.35 \\
\hline
\end{tabular}

Note. $\mathrm{BDI}=$ Beck Depression Inventory; $\mathrm{WAI}=$ Working Alliance Inventory; $\mathrm{t} 2, \mathrm{t} 3, \mathrm{t} 4, \mathrm{t} 5, \mathrm{t} 15=$ session number at which instruments were administered. 
(d) Subgroup with severe depression level: BDI score between 29 and 63 .

Table 4 shows that the four subgroups are not only internally more homogeneous, as is evident from the standard deviations of their BDI means, but more importantly that they have a different initial depression level; BDI scores range from about 4 to 15 , then to 24 and finally to 32 . They are clearly different subgroups in terms of patients' initial depression.

Patients also show a clear difference in symptomatic improvement at session 15: while in the subgroups with "minimal level" and "moderate" depression, the BDI scores decrease by scarcely more than $2-3$ points, the therapeutic response in the "pathological" subgroup is almost twice as strong, and in the "severe" subgroup it is four times as strong (with respect to the minimal depression level).

Another difference pertains to the alliance: The intensity of the patients' early alliance experience is clearly stronger in the two less-depressed subgroups, as it is higher than that of patients in the pathological level and severe level subgroups by 3 to 6 points respectively. The alliance response of initially less-depressed patients also has a stronger increase rate from session 2 to session 5. This confirms what has already been reported (Alberti et al., 2008b), that is, i.e. that initial depression has a negative influence on the formation of early alliance.

However, the most interesting difference between the four subgroups becomes evident when we consider the partial correlations between early alliance, initial depression and early outcome, i.e. a statistical analysis highlighting the correlations of advanced depression with early alliance and initial depression, controlling for respectively initial depression and early alliance (Table 5). In the two groups with respectively moderate and pathological levels of initial depression, early alliance is much more correlated to advanced depression than it is in the extreme groups (i.e., groups with respectively minimal and severe levels of initial depression). This aspect is particularly apparent in the pathological level subgroup, but it is also noticeable in the moderate level subgroup, albeit with a delay and lower intensity.

Another aspect that characterizes the pathological level and the severe level subgroups is the decreasing significance of the correlations between initial depression and advanced depression. In other words, the depressive condition seems to perpetuate itself less in the more severely depressed patients than in those who are slightly depressed.

On one hand, therefore, we have an increasing relationship between early alliance and advanced depression, and on the other hand a decreasing relationship between initial and advanced depression.

\section{The creation of the intermediate level group}

Hoping to highlight this trend and isolating the patients who show the highest early outcome predictivity on the basis of their early alliance scores, we established a fifth subgroup of patients whose BDI scores were in the overlapping area of the moderate level and the pathological level subgroups, that is between 17 and 28 (see Figure 2). As a result of this we identified an intermediate level subgroup including 18 patients.

Descriptive statistics of this subgroup (Table 6) show that it has an intermediate early alliance level, as well as early alliance increase and BDI therapeutic response, but also that it is more internally homogeneous in comparison with both the total patient sample and all other subgroups (see Table 5 ).

The main peculiarities of this subgroup become clear when we examine the partial correlations (Table 7). The first is that partial correlations between WAI at sessions 2, 3, 4, and 5 and BDI depression score at session 15 , controlling for initial depression, are all significant at the $1 \%$ and $5 \%$ level. In no other subgroup is early alliance so strongly and coherently predictive of early outcome.

The second peculiarity is that significantly predictive alliance scores are present at decidedly earlier sessions with respect to the total sample and the other subgroups. The first significant partial correlation coefficient can already be found at session 2 , while the most outcome-predictive WAI score is found at session 3 instead of session 5 .

Therefore, in comparison with all the other subgroups and the total sample, patients with an intermediate initial depression develop an alliance which predicts outcome at session 15 earlier and more strongly, and presumably exerts a more intense influence over it.

Table 7. Partial correlations between advanced depression (session 15) and respectively initial depression (session 2) and early alliance (sessions 2 to 5 ) in the intermediate depression level subgroup, controlling for respectively early alliance and initial depression

\begin{tabular}{lccccc}
\hline Variable & BDI-t2 & WAI-t2 & WAI-t3 & WAI-t4 & WAI-t5 \\
\hline BDI-t15 & 0.19 & $-0.54^{*}$ & $-0.64^{* *}$ & $-0.55^{*}$ & $-0.56^{*}$ \\
\hline
\end{tabular}

${ }^{*} p<.05 ;{ }^{* *} p<.01$

Note $\mathrm{BDI}=$ Beck Depression Inventory; WAI = Working Alliance Inventory; $\mathrm{t} 2, \mathrm{t} 3, \mathrm{t} 4, \mathrm{t} 5, \mathrm{t} 15=$ session number at which instruments were administered 
Table 8. Effects of initial depression (session 2) and alliance (sessions 2, 3, 4, 5 and 15) on advanced depression (session $15)$, for the intermediate level subgroup, as shown by multiple regression analysis

\begin{tabular}{|c|c|c|c|c|}
\hline \multirow[b]{2}{*}{ Variable } & \multicolumn{4}{|c|}{$\mathrm{n}=18$} \\
\hline & $\beta$ & $\mathrm{T}$ & $\mathrm{R}^{2}$ & $\mathrm{~F}$ \\
\hline Model 1 & & & 0.32 & $4.20^{*}$ \\
\hline Constant & 27.64 & 3.35 & & \\
\hline BDI-t2 & 0.28 & 0.86 & & \\
\hline WAI-t2 & $-0.27^{* *}$ & -2.88 & & \\
\hline Model 2 & & & 0.44 & $6.00^{*}$ \\
\hline Constant & 9.83 & 2.67 & & \\
\hline BDI-t2 & $0.71^{* *}$ & 1.70 & & \\
\hline WAI-t3 & -0.13 & -3.46 & & \\
\hline Model 3 & & & 0.33 & $3.85^{*}$ \\
\hline Constant & 14.04 & 2.84 & & \\
\hline BDI-t2 & $0.68^{* *}$ & 1.36 & & \\
\hline WAI-t4 & -0.19 & -2.75 & & \\
\hline Model 4 & & & 0.34 & 2.91 \\
\hline Constant & 7.01 & 2.92 & & \\
\hline $\mathrm{BDI}-\mathrm{t} 2$ & $0.72^{* *}$ & 1.48 & & \\
\hline WAI-t5 & -0.10 & -2.41 & & \\
\hline Model 5 & & & 0.12 & 1.47 \\
\hline Constant & 13.66 & 1.64 & & \\
\hline BDI-t2 & $0.69^{* *}$ & 1.25 & & \\
\hline WAI-t 15 & $-0.17^{* *}$ & -1.42 & & \\
\hline
\end{tabular}

${ }^{*} p<.05 ;{ }^{* *} p<.01$

Note. BDI = Beck Depression Inventory; WAI = Working Alliance Inventory; $\mathrm{t} 2, \mathrm{t} 3, \mathrm{t} 4, \mathrm{t} 5, \mathrm{t} 15=$ session number at which instruments were administered.

Another peculiarity of this subgroup, which is even more important in our view, is the predictive power of initial depression: For the first time we find a partial correlation between BDI-t2 (initial depression) and BDI-t15 (advanced depression) which is not significant, besides being much lower than all the partial correlations between WAI-t2, WAI-t3, WAI-t4, WAI- $t 5$, and BDI-t15. The negative influence on early outcome of the initial symptomatic condition thus practically vanishes, and is replaced by the opposing positive influence of a very early-established alliance.

This particular aspect of the behavior of the intermediate level subgroup with respect to early outcome factors is confirmed by multiple regression analysis.
This analysis shows that the contribution of initial depression (BDI-t2) to advanced depression (BDI-t15) is still positive but constantly not significant, whereas the contribution of alliance, which is obviously negative, is persistent and often highly significant, even at session 2 (Table 8 ). Comparing Table 8 with Table 2 gives clear evidence of the substantial inversion, in intermediately depressed patients, of the relationship between the contribution of initial depression and early alliance to early outcome, in favour of the latter.

Regression analysis also reinforces the previous finding that in this subgroup the early outcome predictive power of the alliance arises earlier: exactly as happened with partial correlations, significant values at the $5 \%$

Table 9. Partial correlations between advanced depression (session 15) and respectively initial depression (session 2) and the three, WAI components Task, Bond and Goal of early alliance (sessions 2 to 5) in the intermediate depression level subgroup, controlling for respectively initial depression and early alliance

\begin{tabular}{|c|c|c|c|c|c|c|c|c|c|c|c|c|c|}
\hline \multirow[b]{2}{*}{ Variable } & \multirow[t]{2}{*}{ BDI-t02 } & \multicolumn{3}{|c|}{ WAI-t2 } & \multicolumn{3}{|c|}{ WAI-t3 } & \multicolumn{3}{|c|}{ WAI-t4 } & \multicolumn{3}{|c|}{ WAI-t5 } \\
\hline & & Task & Bond & Goal & Task & Bond & Goal & Task & Bond & Goal & Task & Bond & Goal \\
\hline BDI-t 15 & 0.19 & -0.07 & -0.28 & 0.09 & $-0.48^{\dagger}$ & 0.22 & 0.05 & -0.02 & -0.04 & -0.31 & -0.37 & 0.13 & -0.24 \\
\hline
\end{tabular}

${ }^{\dagger} p<.10$

Note. $\mathrm{BDI}=$ Beck Depression Inventory; WAI = Working Alliance Inventory; $\mathrm{t} 2, \mathrm{t} 3, \mathrm{t} 4, \mathrm{t} 5, \mathrm{t} 15=$ session number at which instruments were administered. 
level are already present at session 2 . The concomitance of no predictive power of initial depression and of a marked predictive power of alliance at a very early phase of therapy is the most characterizing aspect of patients entering psychotherapy with intermediate severity of depression. In these patients, the therapeutic effect of the alliance, with all its implications, overcomes the strong tendency of initial depression to perpetuate itself in time, hence bringing about positive treatment early outcome.

Table 9 shows the partial correlations between advanced depression (BDI-t15) and respectively initial depression (BDI-t2) and the three WAI components (Task, Bond, and Goal) at each assessment point, controlling respectively for early alliance and initial depression. Although there is some correlation for the Goal and Bond components, the Task component shows a trend to more constant and higher, although non-significant, correlation coefficients with advanced depression. This data suggest that Task is the alliance component mostly contributing to early outcome (see Table 3 ). In the intermediate level subgroup, too, patienttherapist agreement about what needs to be done during sessions is the strongest factor to influence early outcome, and to contribute to breaking the tendency of initial depression to perpetuate in time.

\section{Discussion}

Although this research project was initially explorative, it led us to examine the interaction between early therapeutic alliance, an acknowledged change mediator, and initial depressive symptomatology, another outcome factor, which could be defined as a change moderator from Kazdin's perspective (2007; 2009).

In a previous study (Alberti et al., 2008b) we reported data showing that initial depression affects not only the outcome of therapies but also the change mediator. Apart from the correlation with later depression, those data showed a negative (even significant at session 5) correlation of initial depression and anxiety with early alliance: the more depressed and anxious patients were at the beginning of psychotherapy, the lower their alliance scores were.

In our opinion, the present study has provided more tangible evidence of the influence of initial depression on early alliance by showing that the higher a subgroup's mean initial depression, the lower its mean alliance at sessions 2 to 5 (see Table 4).

Thus, an essential step towards a better understanding of the interaction between the two opposing factors, initial depression and alliance, was to regroup patients in order to examine the early outcome predictive power of different intensity levels of the former, that is the moderating variable, simultaneously monitoring possible variations in early alliance.

The most interesting data regarding these subgroups is reported in Table 5, which shows that in the moderate level subgroup and especially in the pathological level subgroup, a correlation of alliance with later depression develops much earlier than in the other subgroups. Excluding both the minimally and severely depressed patients, we created a single specific subgroup of subjects who, at the beginning of therapy, were affected by a mood deflection of intermediate severity.

Patients with intermediate severity depression showed a peculiar pattern of partial correlations (Table 7): while alliance correlated earlier (starting at session 2) more strongly and consistently with early outcome, initial depression did not correlate with advanced depression. This might be indicative of an inversion of the predictive power of initial depression with respect to the predictive power of early alliance is the peculiar characteristic of this subgroup, showing that the therapeutic effect of alliance, as heralded by early WAI scores, is stronger than the self-perpetuation of initial depression.

Curiously, the intermediate level subgroup had not developed as strong an alliance as the other subgroups had. It was only characterized by the fact that its alliance scores already correlated with the outcome at session 2, which is earlier than in other subgroups. This could be interpreted by suggesting that these patients had a shorter latency in developing trust and confidence in their therapists, and remained "tuned in" to them throughout the course of subsequent sessions. Considering the general relevance of the Task factor for alliance, they presumably also agreed on what needed to be done during sessions earlier than other patients.

The reason why these three aspects, that is faster alliance development, stronger influence of alliance on early outcome, and irrelevance of initial depression as an outcome factor, were observed in patients with intermediate severity initial depression requires a tentative explanation.

Unfortunately, our research design did not include measurements from which we could derive empirical demonstrations that show why such patients should behave in such a way. Therefore, we must limit ourselves to hypotheses that could be tested in future research.

We would like to consider some possible consequences of intermediate severity initial depression. Firstly, a higher degree of suffering compared to less depressed patients could result in patients with intermediate severity depression being more motivated to committing themselves to therapy, which begins with the awareness of their need to ask for and accept help from a therapist.

Secondly, although patients with more severe depression should theoretically be even more motivated to committing themselves to treatment, such patients might well be influenced by other factors that make therapy and cooperation therein more difficult. For example, a more depressed mood may bring about a reduction of energy and a lack of self-confidence.

Moreover, if more severe depression relates to interpersonal issues, there might also be distrust and lower 
propensity to interact, but also, perhaps in the more severe patients, deep relational attitudes, severely dysfunctional relational schemas or attachment difficulties, all of which may hinder building a trusting relationship with the therapist and the procedures he/she proposes. This difficulty in building a trusting relationship might explain why in general very severe mental disorders, as those excluded by our research design, are less suited for psychotherapy.

If patients with intermediate severity depression have a less problematic and dysfunctional relational orientation, this may explain, along with their strong commitment, their higher capacity to establish an alliance and to cooperate with the therapist.

On the other hand, the lower propensity to establish an early alliance which is predictive of an early outcome could be, at least partially, a consequence of our measurement design. As previously described, this ends with session 15 and, thus, does not show potentially good outcomes resulting from longer treatment.

As already stated by Shapiro and colleagues (1994), more depressed patients could develop a good alliance at a slower pace, thereby only producing a good outcome after session 15. An indication of a longer latency in developing an early outcome-correlated alliance comes from the data in Table 5, where we can see that the severe level subgroup reaches a preliminarily significant (i.e., at a $10 \%$ probability level) partial correlation coefficient of over 0.70 by session 5 , whereas the moderate level and pathological level subgroups reach a $5 \%$ significant correlation by session 4 , or even by session 2 . This consideration should, of course, be founded on more data.

On the other hand, a plausible explanation of the total lack of significant alliance-early outcome correlation in the minimal level subgroup is needed. Indeed, these less severely depressed patients who presumably suffer less, are perhaps also less motivated to work on themselves, despite the higher absolute alliance scores (see Table 4). In fact, in this case, we have the apparent paradox of a very high alliance without any correlation with the ensuing early outcome. At the moment, this leads us to the conclusion that the alliance of minimally depressed patients is somehow disconnected from a sufficient commitment to therapeutic work. It might be interesting to see how the WAI factors behave in this subgroup in comparison with the intermediate level subgroup.

Yet again, in connection with the less depressed patients, we should consider the possibility of a methodological limitation consisting in the fact that in this subgroup the WAI and BDI scores lie near the range limit of those measures. We cannot expect relevant variations in scores either for depression, which is already at very low levels, or for alliance, which reaches high scores from the very onset of therapy.

Here we must consider some other general limitations connected with our sample's composition: first, we did not control for the distribution of diagnoses across the two treatment modalities; second, part of the sample was treated, as adjunctive pharmacological treatment, with antidepressants and anxiolythics. Although we think that those differences were somehow overshadowed by the patients' similar clinical condition at intake and by the not too dispersed severity of initial depression, we also think that future research, with perhaps more treatment modalities and particularly with a homogeneous sample composition regarding diagnosis and the presence/absence of pharmacotherapy. could help to highlight the currently unanswered questions.

At this point we should not forget the salient result of the present study, that there are situations in which the intrinsic tendency of depressive suffering to perpetuate itself is counterbalanced and then overcome by a good alliance between patient and therapist, with the ensuing therapeutic processes facilitated by it. Alliance is certainly favored by an adequate combination of preexisting patient and therapist factors: the patient's motivation and capacity to enter a relationship, and the therapist's personality (Lambert, 2004).

Furthermore, it is facilitated and influenced by procedures implemented by the therapist at the beginning and during later phases of therapy. These procedures include a broad array of supportive interventions, the interpretation/explicitation of defensive patterns, the handling of relational complementarity, and others like the wellknown Rogerian attitudes of empathy, acceptation, and unconditioned positive regard (Alberti, 2004).

We think that the most favorable conditions for alliance development, and consequently optimal cooperation between patient and therapist, are those in which the patient's personality and motivational aspects coincide with the therapist's alliance-promoting behavior. This optimal convergence may appear to be static, but it is not necessarily so. The fact that the alliance can be governed and guided within certain limits suggests that the patient's capacity to enter relationships may be modified, provided the therapist modulates his/her attitudes and interventions.

This possibility implies that our research results for a circumscribed subgroup could also be applied to the generality of patients. If a positive alliance reaction is favored by treating patients in certain ways, we can presume that what we have observed in the subgroup of patients with intermediately severe depression may also be true for many other patients, although perhaps with longer delays.

In concluding, we can say that our main hypothesis could be confirmed: patients having an initial different depression level showed a different correlation between early alliance and advanced depression. Moreover, there was no proportional increase of alliance-early outcome correlation parallel to the increase of initial depression level. Rather, an inverse-U-shaped relationship emerged, with patients showing an initial intermediate depression level having a stronger correlation between alliance and early outcome than both the less and the more depressed ones. For the intermediately depressed subgroup of patients the tendency of depression to perpetuate during therapy course was outgrown by the positive effect of a stronger and earlier developing alliance. 


\section{References}

Alberti G. G. (2004). L'antinomia relazione/procedure e l'integrazione tra le psicoterapie [The relationship/procedure antinomy and psychotherapy integration]. Ricerca in Psicoterapia, 7(1), 7-33.

Alberti G. G. (2009). Considerazioni sullo studio scientifico della psicoterapia. In margine a una ricerca sulle variazioni individuali dell'alleanza terapeutica [Considerations on the scientific study of psychotherapy, with reference to a research on individual variations of therapeutic alliance]. In Carere-Comes $\mathrm{T}$. (Ed.) Quale scienza per la psicoterapia? [Which science for psychotherapy?]. Proceedings of the Third SEPI-Italy Conference (pp. 122-143). Firenze: Florence Art Edizioni.

Alberti G.G., Rognoni F., Carozzi A., Alfieri L. (2008a). Un servizio pubblico di psicoterapia: Il Centro Distimie del DSM del San Carlo a due anni dal suo avvio [A public psychotherapy service: The Centro Distimie of the Mental Health Department of Milan's San Carlo Hospital two years after its beginning]. Psichiatria Oggi, 21(1-2), 10-16.

Alberti G.G., Rognoni F., Alfieri L., Carozzi A., Martorano A., Ricchi L., Martini S. (2008b). Osservazioni circa la dinamica di formazione dell'alleanza terapeutica[Observatons about the forming dynamic of the therapeutic alliance]. Ricerca in Psicoterapia 11(2), 139-166.

Alberti G.G., Rognoni F., Carozzi A., Alfieri L., Martorano A., Ricchi L., Martini S. (2008c). La dinamica di formazione dell'alleanza terapeutica e l'esito a breve e medio termine [The forming dynamic of therapeutic alliance and short- and mean-term outcome]. Ricerca in Psicoterapia, 11(2), 167-188.

Beck A.T. \& Steer R.A. (1987). Manual for the revised Beck Depression Inventory. The Psychological Corporation: San Antonio.

Beutler L.E., Malik M., Alimohamed S., Mark Harwood T., Talebi T., Noble S., Wong E. (2004). Therapist variables. In Lambert M.J., Bergin and Garfield's Handbook of Psychotherapy and Behavior Change, $5^{\text {th }}$ Edition (pp. 227-306). New York: Wiley.

Clarkin J.F. \& Levy K.N. (2004). The influence of client variables on psychotherapy. In Lambert M.J., Bergin and Garfield's Handbook of Psychotherapy and Behavior Change. $5^{\text {th }}$ Edition (pp. 194-226), New York: Wiley.

Derogatis L. R. (1977). The SCL-90R. Baltimore Clinical Psychometric Research.

Hamilton M. (1959). The assessment of anxiety states by rating. British Journal of Medical Psychology, 32, 50-55.

Hamilton M. (1960). A rating scale for depression. Journal of neurology, neurosurgery and psychiatry, 23, 51-56.

Hoberman H.M., Lewinsohn P.M. \& Tilson M. (1988). Group treatment of depression: Individual predictors of outcome. Journal of Consulting and Clinical Psychology, 56(3), 393398Horvath A.O. \& Greenberg L.S. (1989). Development and validation of the Working Alliance Inventory. Journal of Counseling Psychology, 36, 223-233.

Horvath A.O. \& Symonds B.D. (1991). Relation between working alliance and outcome in psychotherapy: a meta-analysis, Journal of Counseling Psychology, 38,139-149.

Kazdin A.E. (2007). Mediators and mechanisms of change in psychotherapy research. Annual Review of Clinical Psychology, 3, 127.

Kazdin A.E. (2009). Understanding how and why psychotherapy leads to change. Psychotherapy Research, 19, 418-428.

Lambert M.J.(2004). Bergin and Garfield's Handbook of Psychotherapy and Behavior Change. $5^{\text {th }}$ Edition, New York: Wiley.

Lambert M.J. \& Ogles B.M. (2004). The efficacy and effectiveness of psychotherapy. In Lambert M.J., Bergin and Garfield's Handbook of Psychotherapy and Behavior Change. $5^{\text {th }}$ Edition (pp. 139-193), New York: Wiley.

Lingiardi V. (2002). L'alleanza terapeutica. Teoria, clinica e ricerca [Therapeutic alliance. Theory, practice and research]. Milano: Raffaello Cortina.

Martin D.J., Garske J.P. \& Davis M.K. (2000). Relation of the therapeutic alliance with outcome and other variables: A meta-analytic review. Journal of Consulting and Clinical Psychology, 68, 438-450.

Overall J. E. \& Gorham D.R. (1962). The Brief Psychiatric Rating Scale. Psychological Reports, 10, 799-812.

Safran J.D. \& Muran J.C. (2000). Negotiating the therapeutic alliance. A relational treatment guide. New York: Guilford.

Shapiro D.A., Barkham M., Rees A., Hardy G.E., Reynolds S. \& Startup M. (1994). Effects of treatment duration and severity of depression on the effectiveness of cognitive-behavioral and psychodynamic-interpersonal psychotherapy. Journal of Consulting and Clinical Psychology, 62, 522-534.

Zung W. W. K. (1965). Self-rating depression scale. Archives of General Psychiatry, 12, 63-70.

Zung W. W. K. (1971). A rating instrument for anxiety disorders. Psychosomatics, 12, 371-379.

Received June 13, 2013

Revision received October 27, 2013 Accepted December 30, 2013 